\title{
MULHER: SONHO, RAZÃO E PODER
}

\author{
Flávia Regina Ramos Gonzaga * \\ Cláudia Maria de Mattos Penna * \\ Marta Machado Verdi *
}

\begin{abstract}
RESUMO - O texto apresenta uma síntese do filme "Mulher: Sonho, Razāo e Poder", no qual as autoras discutem as relações de poder presentes no cotidiano de uma enfermeira. O eixo principal se estabelece em torno da condição da mulher e da enfermagem profissional na sociedade brasileira. A reflexão, enriquecida com recortes de vários -studiosos contemporâneos do tema "poder", percorre três momentos: - o confronto consigo mesma, - o despertar para a realidade, e - a tomada de consciência do poder. O objetivo do trabalho foi estabelecer a trajetória do processo de amadurecimento pessoal e profissional que culmina numa nova visão de si e da profissão e recupera a consciência da diversidade e do potencial de oposição às forças que condicionam a realidade impondo-lhe novo rumo.
\end{abstract}

\begin{abstract}
A synthesis of the film "Woman: dream, reason and power" where the authors discuss the relationship of power presented in a nurse's everyday life. The plot is around a woman and professional nursing in Brazilian society. The reflexion, enriched by many contemporary researches on power theme idea goes through three moments:- herself confrontation, awakening to reality and - power awareness. The objective task has been to establish the personal and professional growth looking for herself and for a profession new view.
\end{abstract}

\section{INTRODUÇÃO}

Nós, como enfermeiras, temos procurado nos últimos anos refletir a nossa prática no sentido de retomar nossa história, questionar nossos valores, ampliar nosso saber num contínuo redimensionamento e abertura de novas perspectivas que respondam ao contexto sócio-polftico em que nos inserimos.

No entanto, percebemos que, ao voltarmos nosso olhar para "o profissional", muitas vezes nos despimos "do particular", daquilo que nos diferencia, do que nos imprime uma maneira própria de ser, perceber e agir no mundo. Deste modo consideramos que uma profissão como a enfermagem, eminentemente feminina, traz em si traços que geram peculiaridades na forma de inserir-se socialmente como trabalho, de articular-se com outros processos de trabalho, de estabelecer relações internas enquanto categoria profissional, enfim no modo próprio de imbricar-se na dinâmica social.

Com isto não desejamos apresentar uma visão reducionista à complexa rede de aspectos que devem ser considerados ao analisarmos criticamente uma profissão. Apenas, escolhemos como foco desta reflexão as relações de poder que permeiam o cotidiano da enfermeira, enquanto mulher que vive numa sociedade patriarcal e enquanto profissional que está submetida a um modelo hegemônico de organização do trabalho em saúde que tende a reproduzir a ordem social estabelecida.

A partir dessa idéia, resolvemos buscar uma forma de provocar a reflexão e o debate do assunto que não se tornasse apenas uma teorização do tema, mas que relacionasse o referencial teórico com a vivência diária pessoal e profissional. Além disso, temos como objetivo favorecer um contato mais estimulante e dinâmico com os estudiosos do assunto, que normalmente não são acessíveis à nossa categoria e, ao mesmo tempo, mesclá-los com formas de expressão mais universais como a poesia e a música, mas que refletem uma análise mais critica da realidade e o atual momento histórico-social.

Considerando os objetivos propostos, escolhemos como estratégia de discussão do tema a apresentação de um vídeo que acreditamos, sintetize um conjunto de idéias que pode ser um

\footnotetext{
* Enfermeiras Mestrandas em Assistência de Enfermagem, Universidade Federal de Santa Catarina
} 
referencial para o debate.

\section{MULHER, SONHO RAZÃO E PODER}

Todo o desenvolvimento do tema ocorre a partir de um personagem fictício que pensa em sua interioridade, na sua profissão, na sua condição feminina e no mundo onde vive. Trata-se de uma enfermeira que está questionando sua trajetória de vida e as perspectivas de transformaçōes individual e coletiva.

No primeiro momento, ela se encontra em uma perspectiva mais pessoal onde relembra seus projetos, seus sonhos e realizaçōes e se depara com uma poesia citada por FREIRE ${ }^{2}$ :

"Só conheço dois caminhos, os mesmos que aprendi quando menina.

Num, o coração se abre verdadeiro

desmanchado em mágoas,

lágrimas e tristezas de amor.

Noutro, sobreviver é imperativo

e a raiva alimenta a vida.

A primeira alternativa

me descobre vulnerável e nua,

me mata.

A segunda me consome

a doçura e o prazer

morro.

E como, até hoje, me deparo

na mesma, encruzilhada,

escolho a vida".

(MARGARIDA apud FREIRE ${ }^{2}$ ).

Desta forma, ela questiona as opções que fez frente a vida e como se percebe subjugada em seu cotidiano, onde suas vontades estão frágeis diante de outras vontades que lhe são impostas. Pensa o que representa como indíviduo e a postura que deve assumir frente ao futuro. Confronta-se consigo própria através de GUATTARI e ROLNIK':

"Quem é você? Você que ousa ter uma opinião, você fala em nome de quê? $\mathrm{O}$ que você vale na escala de valores reconhecidos enquanto tais na sociedade? A que corresponde sua fala? Que etiqueta poderia classificar você? E somos obrigados a assumir a singularidade de nossa própria posição com o máximo de consistência. . . Só que isso é freqüêntemente impossível de fazermos sozinhos, pois uma posição implica sempre numa organização coletiva. É como se nosso direito de existência desabasse. E af se pensa que a melhor coisa que se tem a fazer é calar e interiorizar valores".
Assim, passamos para um segunuu inumento, onde o pensamento da personagem se desloca do foco pessoal para o coletivo e ela relembra seu perfodo de formação profissional e o contexto sócio-político que envolve a profissão. Ela analisa as possibilidades de enfrentamento e singularização* que viabilizem formas de se opor a reprodução dos modelos que sustentam a estrutura vigente. Para isso, considera necessário mais do que uma força pessoal, um projeto político de transformação que envolva uma mobilização da categoria, mas que se amplie para a dinâmica dos movimentos sociais.

Neste momento, ocorre seu encontro com FOUCAULT ${ }^{4}$ e GUATTARI ${ }^{5}$ que analisam:

"Onde não há poder, há resistência, e, no entanto, esta nunca se encontra em posição de exterioridade em relação ao poder. . . Os pontos de resistência estão presentes em toda rede de poder (. . .) os focos de resistência disseminam-se (. . .) provocando o levante de grupos e indivíduos de maneira definita, inflamando certos pontos do corpo, certos momentos da vida, certos tipos de comportamento. . . E é certamente a codificação estratégica desses pontos de resistência que torna possível uma revolução".

\section{(FOUCAULT ${ }^{4}$ ).}

"A luta de classes não passa mais simplesmente por um front delimitado entre os proletários e os burgueses, facilmente detectável nas cidades, nos vilarejos; ela está igualmente inscrita através de numerosas estigmas na pele e na vida dos explorados, pelas marcas de autoridade, de posição, de nível de vida; $e$ preciso decifrá-la a partir do vocabulário de uns e de outros, seu jeito de falar, a marca de seus carros, a moda de suas roupas, etc. Não tem fim! (. . .) De que serve afirmar a legitimidade das aspirações das massas se o desejo é negado em todo o lugar onde tenta vir à tona na realidade cotidiana? . . . Pois na ausência de desejo a energia se autoconsome sob a forma de sintoma, de inibição de angústia. E pelo tempo que já estão nessa, já podiam ter se dado conta destas coisas por si mesmo".

(GUATTARI').

Passamos, então, para o $3^{\circ}$ momento em que ela toma consciência do poder que pode emergir dessa prática de organização coletiva. Ao perceber esse caminho, ela não despreza as

\footnotetext{
* Singularizaçåo - termo usado por GUA TTARI, para diferenciar de individualidade quando afirma que todo "processo de transformaçăo passa pela singularidade" e que esta se faz "emprestando, associando, aglomerando dimensóes de diferentes especies". GUA T TARI e ROLNIK" , (Micropolítica: cartografia do desejo, 1986, p.37)
} 
possíveis microtransformações que possam ocorrer. Com esta constatação ela se reporta a uma situação de sua experiência profissional quando estabelece um diálogo que contrapõe a visão revolucionária à uma visão incógnita oposicionista*. Com esse diálogo ela manifesta o seu reconhecimento e compreensão das relaçōes de poder da realidade e declara seu potencial de contrapô-lo. Porque mesmo que não nos deixem correr, ainda andaremos; mesmo que não nos deixem andar, ainda moveremos; mesmo que não nos deixem mover, ainda poderemos ver; mesmo que não nos deixem ver, ainda sentiremos; mesmo que não nos deixem sentir, mesmo assim, ainda pensaremos. . . Porque é no livre campo da consciência que germinam as transformaçōes. . .

No entanto, mobilizar esse potencial não é uma tarefa simples, pois existe uma complexa rede de mecanismos sociais que buscam ocultar e sufocar qualquer iniciativa que visem sua emergência. Por isso GOETHR citado por HELLER $^{7}$ alerta:

\footnotetext{
“Que não te despojem

de teu sentido inicial.

É fácil crer no que

crê a multidão.

Fortalece teu entendimento

de um modo natural;

difícil é saber

o que é saber".
}

A adversidade está justamente no reconhecimento do poder que possui, na capacidade de união, na postura revolucionária que tem como um dos instrumentos a própria construção de uma identidade individual e coletiva que vai impulsionar a ação transformadora. Com essa idéia, ela conclui sua reflexão trazendo como proposição que guie sua prática o pensamento de GRAMSCI apud FRIGOTTO:

"Instruí-vos porque temos necessidade de toda a nossa inteligência. Agitai-vos porque temos necessidade de todo nosso entusiasmo. Organizai-vos porque temos necessidade de toda a nossa força".

\section{CONCLUSÃO}

Como foi dito anteriormente este trabalho buscou como foco principal a análise das relações de poder presentes na sociedade atual e especificamente na vida da mulher-enfermeira. No entanto, o texto aqui apresentado é uma síntese com alguns elementos básicos que compōem o roteiro original do vídeo.

Nele, a rajetória da reflexão do personagem percorre três momentos fundamentais e interrelacionados: o confronto consigo mesmo, o despertar para a realidade e a tomada de consciência do poder. Esses momentos nada mais são do que representações do que julgamos ser o processo contínuo de amadurecimento pessoal e profissional que nos torna capaz de fazer uma escolha e nos enganjar ou não à luta de transformação da realidade e da construção consciente da história.

Esperamos que este trabalho, aliado aos que já levantaram essas questões e a outros que poderão aprofundá-las, venha contribuir para as discussões que busquem o redimensionamento da prática profissional da enfermagem. Não esquecendo que "até aqui as possibilidades da mulher foram sufocadas e perdidas para a humanidade; já é tempo, em seu interesse e no de todos, de deixá-la enfim correr todos os riscos, tentar a sorte". (BEAUVOIR ${ }^{1}$ ).

\section{REFERÊNCIAS BIBLIOGRÁFICAS}

1. BEAUVOIR, Simone. $O$ segundo sexo: a experiência vivida. 6 ed. Rio de Janeiro: Nova Fronteira, 1980.

2. FREIRE, Roberto. Ame e dê vexame. 8. ed. Rio de Janeiro: Guanabara Koogan, 1990.

3. FRIGOT TO, Gaudêncio. Au la inaugural da fundação da Escola Politécnica de Saúde Joaquim Venâncio. Caderno de Saúde Pública. ENPS/FIOCRUZ, 4 (4) out./dez. 1988.
4. FOUCAULT, Michel. Microflisica do poder. 9. ed. Rio de Janeiro: GRAAL. 1990. 295p.

5. GUAT TARI, Felix. Revoluçōes moleculares: pulsaçōes políticas do desejo. 3. ed. São Paulo: Brasiliense. 1987. 229 p.

6. GUAT TARI, Felix e ROLNIK, Suely. Micropolitica: cartografias do desejo. 2. ed. Petrópolis: Vozes, 1986.

7. HELLER, Agnes. $O$ cotidiano e a história. 3. ed. Rio de Janeiro: Paz e Terra, 1989.

\footnotetext{
* Visāo incógnita oposicionista, segundo HELLER ${ }^{7}$ (p. 98-106), é aquela que encontra-se em contraposição do mundo em que vive. Nảo se sente a vontade na realidade, sofre com os papeis que tem que representar, mas nảo consegue manifestar-se, depor o seu incógnito. Nâo é um conformista, mas tampouco chega a ser um revolucionário (. . . e) é um rebelde.
} 